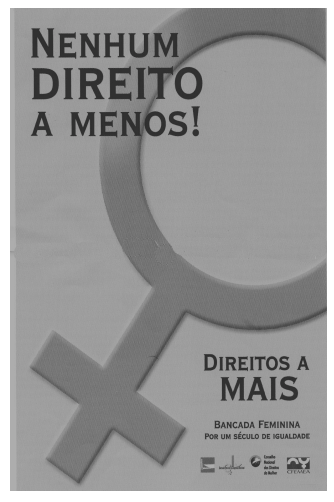

\title{
AÇÕES E ESTRATÉGIAS DO CNDM PARA O "EMPODERAMENTO" DAS MULHERES'
}

\section{SOLANGE BENTES JUREMA}

Resumo: Situando a temática do acesso ao poder como uma prioridade para a atual gestão do CNDM, a exposição traz um rápido diagnóstico da participação das mulheres no Executivo e no Judiciário e cita estratégias, ações e compromissos que o Conselho tem assumido, nas últimas gestões, com o fito de contribuir para o aumento da presenças das mulheres nos espaços de poder.

Palavras-chave: empoderamento, mulher, ações, compromissos, participação

O Conselho Nacional dos Direitos da Mulher é fruto da capacidade de organização e pressão dos movimentos feministas e das mulheres brasileiras. As suas ações ao longo destes 15 anos de existência refletem, de certa forma, as demandas e plataformas destes movimentos e das Conferências Internacionais sobre os Direitos da Mulher realizadas pela ONU. É na década de noventa, quando a participação política das mulheres passa a ser uma das suas bandeiras de luta - não apenas no Brasil, mas no âmbito internacional - que o CNDM incorpora esta problemática no seu Programa de Ação, tendo como referência a Plataforma de Ação Mundial (PAM) aprovada na IV Conferência Mundial sobre a Mulher, em 1995 (Beijing, China). A atual gestão do CNDM (outubro/1999-2003) elegeu como um dos eixos básicos da sua atuação o acesso das mulheres ao poder.

\footnotetext{
1 Exposição realizada no Seminário Mulheres na política: mulheres no poder, realizado pelo CFEMEA, CNDM, Bancada Feminina no Congresso Nacional e outras entidades, em Brasília, de 16 a 18 de maio de 2000.
} 


\section{AÇÕES E ESTRATÉGIAS DO CNDM PARA O "EMPODERAMENTO" DAS MULHERES}

Na nossa exposição faremos um rápido diagnóstico da participação das mulheres no aparelho do Estado, com ênfase no Executivo e no Judiciário; trataremos das ações e compromissos assumidos pelo CNDM quanto ao "empoderamento" das mulheres na gestão passada e na atual gestão, bem como das estratégias adotadas pelo Conselho Nacional para este fim.

\section{Participação das mulheres nos espaços de poder no Brasil}

A participação das mulheres nos espaços de poder no Brasil ainda é extremamente baixa. De acordo com o Índice de Desenvolvimento Humano (PNUD/ 1999), o Brasil está no septuagésimo nono lugar no que se refere aos indicadores de desigualdades entre os sexos na participação política. É uma situação mais desfavorável do que a de países como o Kasaquistão, as Filipinas e a Arábia Saudita. Para alcançar cargos mais altos nas hierarquias de poder, as mulheres brasileiras precisam enfrentar o poderoso traço cultural segundo o qual estas ainda não são facilmente admitidas em posições de decisão e comando.

Além da baixíssima participação das mulheres no Poder Legislativo, sobretudo no Congresso Nacional, é quase insignificante a participação feminina nos Poderes Executivo e Judiciário no Brasil. Senão vejamos:

\section{Participação das mulheres no Poder Executivo, no âmbito Federal}

O diagnóstico realizado pelo MARE, em abril de 1998, através do Programa Nacional de Igualdade de Oportunidade na Função Pública, realizado por iniciativa do CNDM, apresenta os seguintes resultados:

As mulheres representam no Brasil o elevado percentual de $44,18 \%$ do contingente de servidores da Administração Pública Federal, mas enfrentam grandes dificuldades para assumir cargos de chefia e de tomadas de decisão. É nos cargos comissionados que encontramos o maior enforcamento da participação feminina na Administração Pública Federal. Dos 136 servidores "DAS-6" (Direção de Assessoramento Superior, as funções mais altas no Poder Executivo), somente 18 são mulheres, o equivalente a $13,24 \%$, enquanto que elas ocupam $45,53 \%$ dos DAS 1. Ou seja, quanto maior o poder de decisão, menor é a participação feminina, sobretudo das mulheres negras. $82,80 \%$ destes Cargos de Comissão (DAS) são assumidos por mulheres brancas.

No Ministério das Relações Exteriores, apenas cinco dos 98 embaixadores do Brasil são mulheres. Até 1998, só existiram no Brasil sete Ministras - número que deixa o Brasil em situação inferior ao restante da América Latina e da África. Atualmente não temos nenhuma Ministra e temos apenas duas Secretárias Nacionais.

Vale ainda ressaltar que segundo o referido diagnóstico as funcionárias públicas se concentram em Ministérios e órgãos da área social - no Ministério da Previdência, as mulheres representam $63,38 \%$ do total de funcionários. Já nas 
áreas econômicas, este percentual é bem menos expressivo, com exceção dos Ministérios da Indústria e Comércio e o do Planejamento e Orçamento, que apresentam mais mulheres: $52,42 \%$ e $51,10 \%$ respectivamente.

\section{Particlpação das mulheres no Poder Judiciário, no âmblto Federal}

As juízas já representam mais de $25 \%$ dos postos de magistrados existentes na Justiça Federal, e na Justiça Comum de $1^{\text {a }}$ Instância elas são em torno de $40 \%$, graças à aprovação das mulheres em concursos públicos. No entanto, os postos mais importantes na hierarquia do Poder Judiciário ainda são ocupados majoritariamente por homens.

No Supremo Tribunal Federal não existe nenhuma mulher. É reivindicação do CNDM que a próxima vaga para o Supremo seja ocupada por uma mulher. ${ }^{2}$ Dos 93 cargos dos Tribunais Superiores - STF, STJ, TSE, TST e Superior Tribunal Militar , apenas dois postos são ocupados por mulheres, no Superior Tribunal de Justiça. ${ }^{3}$ No Tribunal Superior do Trabalho - o primeiro Tribunal Superior a ter mulheres como Ministra - desde 1999 todos os Ministros voltaram a ser do sexo masculino.

O CNDM entende que num país como o Brasil, onde $51 \%$ da população é feminina, a participação igualitária das mulheres no processo de tomadas de decisões é fundamental para o fortalecimento da democracia e para que a composição da sociedade esteja realmente refletida na função pública, nas políticas públicas e na legislação do país.

É com base nesta realidade, e nas premissas da Plataforma de Ação Mundial acima mencionadas, que o CNDM se tem empenhado em desenvolver ações que possam contribuir para o "empoderamento" das mulheres, seja buscando influenciar na definição de políticas públicas e elaboração das leis que possam contribuir neste sentido, seja desenvolvendo ações e Campanhas Nacionais de sensibilização da sociedade. Para isso, tem procurado associar-se às entidades e movimentos de mulheres envolvidos nesta luta.

\section{Ações e/ou Compromissos do CNDM quanto do "empoderamento" das mulheres}

\section{Gestão anterior (1995 a 1999)}

O CNDM empenhou-se nesta questão praticamente desde o início, quando os movimentos feministas e de mulheres brasileiros passam a incluir na sua pauta a conquista de novos direitos (a partir de 1995) - tais como o estabelecimento de cotas para as candidaturas de mulheres no legis/ativo -, ou seja, quando

\footnotetext{
${ }^{2}$ Em dezembro de 2000 assumiu a primeira mulher, Ministra Ellen Gracie.

${ }^{3}$ Ministras Eliana Calmon e Fátima Nancy.
} 


\section{AÇÕES E ESTRATÉGIAS DO CNDM PARA O "EMPODERAMENTO" DAS MULHERES}

passam a preocupar-se com a participação das mulheres nos espaços de poder e tomada de decisão. Inicia-se então a luta pela implantação de ações afirmativas na política, nomeadamente pela adoção das cotas. Estas foram implantadas no Brasil a partir das eleições de 1996 (com base na Lei Eleitoral $n .^{\circ}$ 9.100 de 1995, que obriga os partidos políticos nas eleições municipais de 1996 a inscreverem no mínimo $20 \%$ de mulheres nas suas chapas proporcionais - Parágrafo $3^{\circ}$ do Artigo 11 ).

Neste período, o CNDM desenvolveu as seguintes ações referentes ao "empoderamento" das mulheres:

Participação na Campanha Nacional "Mulheres sem Medo do Poder", realizada em 1996 pela Bancada Feminina do Congresso Nacional, movimentos de mulheres e várias entidades da sociedade civil (IBAM, CFMEA, etc.), com o apoio do PNUD e UNIFEM.

Em 1998, em parceria com o Ministério da Administração e Reforma do Estado (MARE), o CNDM deu início à realização do Programa Nacional de Promoção da lgualdade de Oportunidade na Função Pública, através da assinatura do Protocolo de Intenções entre Ministério da Justiça e MARE, por ocasião das comemorações do Dia Internacional da Mulher. O referido Programa contemplava várias ações, dentre as quais destacamos as que se seguem: a) diagnóstico sobre a participação de homens e mulheres na Administração Federal; b) elaboração, pelos órgãos da Administração Pública Federal, de Planos Bianuais para a Promoção da lgualdade de Oportunidade na Função Pública (até dezembro de 1998, já haviam apresentado seus Planos os seguintes órgãos: AGU [Advocacia Geral da União], Casa Militar e os Ministérios da Cultura, Exército, Justiça, Meio Ambiente, Relações Exteriores e a Universidade Federal de Sergipe); c) promoção de Cursos de Formação voltados para a capacitação de mulheres para assumirem cargos de chefia no setor público (em 1998, foram realizados três cursos: um na ENAP e dois na ESAF); d) ações de sensibilização dos homens e mulheres sobre a importância da participação das mulheres nos cargos de chefia.

\section{Atual gestão (outubro 1999 - 2003)}

A atual gestão do CNDM elegeu como uma de suas prioridades desenvolver ações que possam contribuir para o "empoderamento" das mulheres. Demos especial atenção a esta questão este ano por se tratar de um ano eleitoral haverá eleições municipais para as Prefeituras e Câmaras de Vereadores(as).

Assim sendo, o Projeto MJ/ SEDH/CNDM/UNIFEM para este ano tem como um dos seus eixos básicos de atuação realizar ações que contribuam para que as mulheres concorram aos cargos eletivos municipais e estaduais do Executivo e Legislativo, prevendo-se a realização das seguintes atividades:

a) realização de atividades de sensibilização e capacitação de candidatas aos cargos eletivos para o Executivo e Legislativo, em parceria com outras entida- 
des. O presente Seminário, "Mulheres na Política, Mulheres no Poder", que estamos realizando em parceria com o CFMEA e a Bancada Feminina do Congresso Nacional, é parte deste Programa;

b) a partir dos dados fornecidos pelo TSE, disponibilização de indicadores sobre o percentual de candidatas inscritas nas eleições estaduais e municipais e percentual de mulheres eleitas no Executivo e Legislativo estadual e municipal.

Além das ações previstas neste Projeto, o CNDM também decidiu participar da reedição da Campanha Nacional "Mulheres sem medo do Poder", a ser realizada este ano pela Bancada Feminina do Congresso nacional, CFEMEA, IBAM e movimentos de Mulheres com o apoio da UNIFEM e outros organismos internacionais. Está-se ainda em busca de financiamento para a realização desta Campanha, através da UNIFEM. Uma vez conseguidos os recursos, ela deverá incluir a realização das seguintes atividades:

- Cursos de capacitação para candidatas às Prefeituras e Assembléias Legislativas;

- produção de material formativo e informativo para as candidatas a estes cargos eletivos: cartilha, vídeos, etc.;

- Campanha nos meios de comunicação para sensibilização da sociedade quanto à importância de se elegerem mulheres para o Executivo e Legislativo, com utilização do horário gratuito do TSE;

- sítio da Internet com informações sobre Mulher e Política. Como esta é uma atividade realizada em parceria, cada entidade terá sua função específica no conjunto das ações a serem realizadas.

O CNDM está também em busca dos meios para produzir um vídeo. Este versaria sobre o resgate histórico da luta das mulheres brasileiras pela participação política, e conteria informações práticas sobre campanha eleitoral. Trata-se de um instrumento para uso das mulheres candidatas a cargos eletivos, e deve estar disponível o mais tardar no final de julho.

\section{Estratégias do CNDM quanto ao "empoderamento" das mulheres}

Para desenvolver as ações com o fito de ampliar a participação das mulheres nos espaços de poder e estimulá-las para que concorram a cargos eletivos, 0 CNDM utilizará, basicamente, as estratégias que se seguem:

- Realização de ações conjuntas com a Bancada Feminina do Congresso Nacional, entidades da sociedade civil envolvidas com a questão - CFEMEA, IBAM, etc. - e movimentos de mulheres, a exemplo da Campanha Nacional "Mulheres Sem Medo do Poder".

- Assinatura de um Protocolo de Cooperação (Intenções) com os Partidos Políticos, visando obter destes últimos o compromisso em assegurar o cumprimento da "Lei de Cotas", com o apoio político efetivo às candidaturas de mulhe- 


\section{AÇÕES E ESTRATÉGIAS DO CNDM PARA O "EMPODERAMENTO" DAS MULHERES}

res, e sobretudo com a garantia das condições materiais e financeiras às mesmas. Este Protocolo deverá incluir as seguintes ações e compromissos: a) preparação didática dos quadros partidários nos Institutos de Estudos e Pesquisas, quanto às questões de Gênero; b) monitoramento das candidatas inscritas pelos partidos no que diz respeito à preparação, organização e articulação das campanhas femininas; c) justa distribuição de tempos de rádio e televisão; c) material de campanha e fundo financeiro partidário; d) regulamentação dos Núcleos Partidários de mulheres objetivando o emprego restrito dos benefícios às próprias mulheres candidatas; e) "empoderamento" das mulheres dentro da estrutura do próprio partido (Direção e Executivas partidárias).

O CNDM também tem procurado desenvolver ações articuladas com os Conselhos de Direitos da Mulher (estaduais e municipais) tendo em vista estimular estes Conselhos a que se envolvam no processo eleitoral do seu estado ou município, de forma a ampliar a participação das mulheres nos cargos eletivos. Nessa perspectiva, trouxemos para esse Seminário todos os Conselhos Estaduais de Direitos da Mulher e procuramos obter dos mesmos o compromisso de envolver, nesse processo, os Conselhos Municipais de Direitos da Mulher dos seus estados.

CNDM Actions and Strategies for Women's Empowerment

Abstract: Considering the topic of access to power as the priority of current CNDM leadership, this paper makes a quick diagnosis of women's participation in Executive and Judiciary powers and cites the strategies, actions and commitments that the Council has adopted, under recent administrations, geared toward contributing to women's increased presence at the sites of power. Keywords: empowerment, women, actions, commitments, participation. 